

\section{DISCLAIMER}

This report was prepared as an account of work sponsored by an agency of the United States Government. Neither the United States Government nor any agency Thereof, nor any of their employees, makes any warranty, express or implied, or assumes any legal liability or responsibility for the accuracy, completeness, or usefulness of any information, apparatus, product, or process disclosed, or represents that its use would not infringe privately owned rights. Reference herein to any specific commercial product, process, or service by trade name, trademark, manufacturer, or otherwise does not necessarily constitute or imply its endorsement, recommendation, or favoring by the United States Government or any agency thereof. The views and opinions of authors expressed herein do not necessarily state or reflect those of the United States Government or any agency thereof. 


\section{DISCLAIMER}

Portions of this document may be illegible in electronic image products. Images are produced from the best available original document. 
DE83 009271

UC-66b

Issued: February 1983

\title{
Analysis and Thermal=Design Improvements of Downhole Tools for Use in Hot-Dry Wells
}

\author{
Gloria A. Bennett \\ Gail R. Sherman*
}

\section{DISCLAIMER}

This report was prepared as an account of work sponsored by an agency of the United States Government. Neither the United States Government nor any agency thereof, nor any of their employees, makes any warranty, express or implied, or assumes any legal liability or responsibility for the accuracy, completeness, or usefulness of any information, apparatus, product, or process disclosed, or represents that its use would not infringe privately owned rights. Reference herein to any specific commercial product, process, or service by trade name, trademark, manufacturer, or otherwise does not necessarily constitute or imply its endorsement, recommendation, or favoring by the United States Government or any agency thereof. The views and opinions of authors expressed herein do not necessarily state or reflect those of the United States Government or any agency thereof.

-Summer Student at Los Alamos. Department of Electrical Engineering, Washington University, St. Louis, MO 63130.

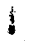


CONTENTS

Page

ABSTRACT

1

I. INTRODUCTION

II. BACKGROUND 3

III. THERMAL ANALYSIS

IV. RESULTS 12

V. DESIGN IMPROVEMENTS

REFERENCES 
ANALYSIS AND THERMAL DESIGN IMPROVEMENTS

OF DOWNHOLE TOOLS FOR USE IN HOT DRY WELLS

by

Gloria A. Bennett and Gail R. Sherman

\section{ABSTRACT}

This report describes design improvements made for downhole thermal protection of systems based on results obtained from the analysis of the electronics, heat sink, and dewar packaged in a steel tubular body. Results include heat flux at the tool surface, temperature-time histories of each subsystem and isotherm contour plots during the simulation. The analysis showed that the thermal potential between the electronics and the heat sink was in the wrong direction and al so was too small to remove heat entering the electronics section. Also, the conductance of the available heat transfer paths from electronics to heat sink was too small to remove that heat efficiently.

Significant improvements in survival at high temperatures were achieved by increasing the available thermal capacity of the heat sink, increasing the thermal potential between the heat sink and electronics, and vastly increasing the conductance of the heat transfer paths.

\section{INTRODUCTION}

The goal of the Hot Dry Rock (HDR) Program is to investigate the feasibility of extracting thermal energy from naturally hot, but essentially dry formations, by circulating water from an injection well through artificially made hydraulic fractures to a production well drilled nearby (Fig. 1). The 


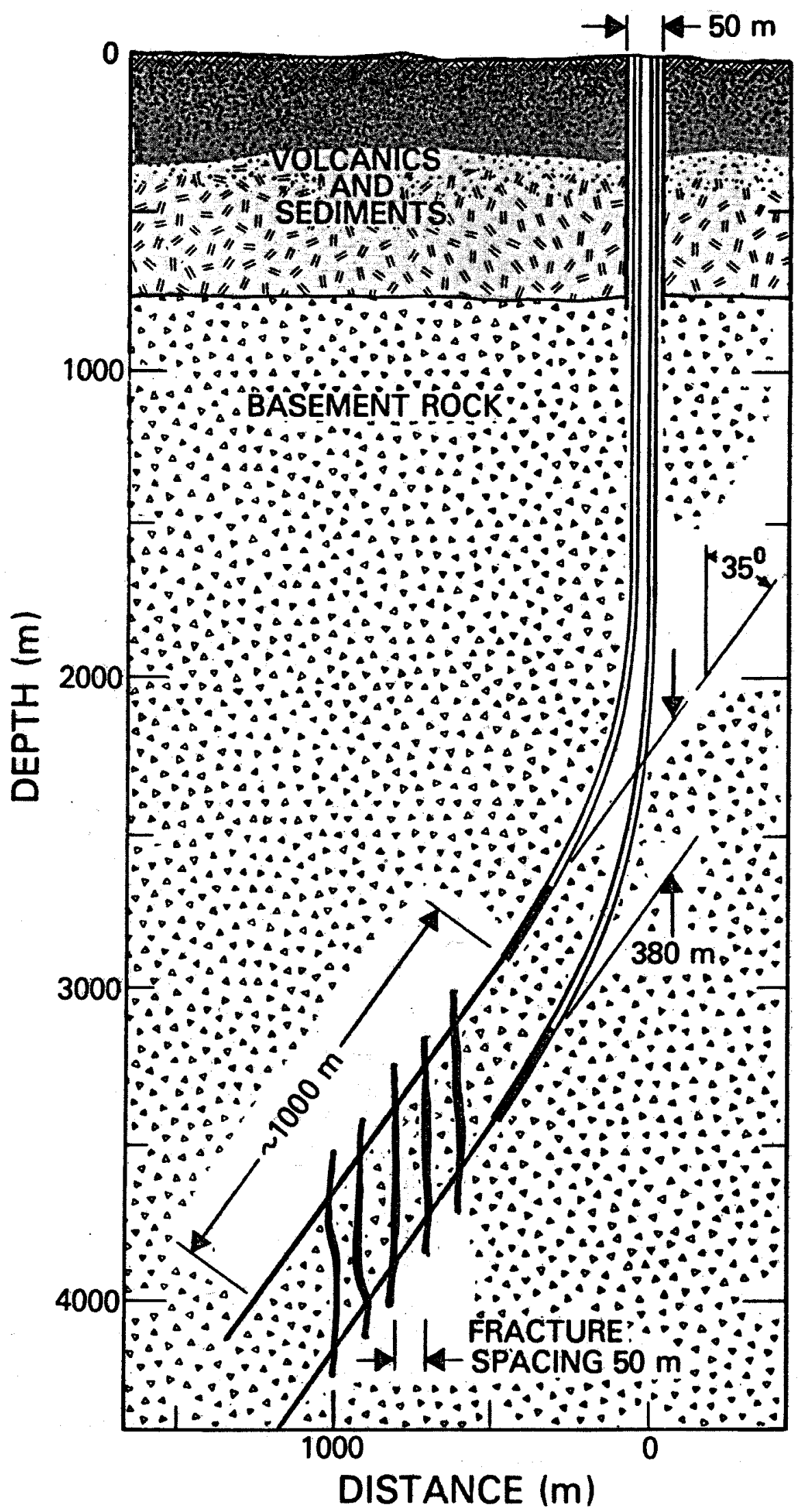

Fig. 1. Fenton Hill site geothermal wells. 
development of techniques leading to acceptable models for energy extraction requires extensive data about water chemistry; acoustic signals, temperature. temperature changes, pressure, and flow rates at various depths in and between the two wells. The tools and downhole electronics used in making these physical measurements must withstand the heat and severe mechanical wellbore conditions to which they are repeatedly subjected. The purpose of this investigation is to define the thermal conditions imposed on the tools and determine the heat fluxes and the temperature field as a function of time. Conditions in many geothermal wellbores of commercial interest are hostile beyond endurance to most conventional oil-well tools and equipment. Water environments in different geothermal fields may vary between acidic salt brines to very basic solutions, each at temperatures well above ambient.

The two wellbores at the Fenton H111 site (FHS), which are being used to develop a commercial size reservoir are about $4600 \mathrm{~m}$ deep, have a bottom-hole temperature of $593 \mathrm{~K}$ and a hydrostatic pressure of $40.3 \times 10^{6} \mathrm{~Pa}$. The bottom $1200 \mathrm{~m}$ of each wellbore is open hole and is inclined at $35^{\circ}$ to the vertical. 1 Because of substances introduced during the drilling process; water chemistry: in the FHS wells can vary between neutral, $\mathrm{pH}=7$ to very basic, $\mathrm{pH}=11$. Such conditions require downhole electronic tools to be packaged in a pressure vessel that can withstand abrasion from the rough granite and corrosion from the drill-hole water. Each tool must be thermally hardened to survive high temperatures long enough to gather data or make the measurement required. Problems arise when measurements must be made at temperatures above the upper limit of $480 \mathrm{~K},{ }^{2}$ which occurs at FHS well depths below $3000 \mathrm{~m}$. Given an average logging velocity in the open hole, tools must have a minimum thermal life of approximately $4 \mathrm{~h}$ in the FHS wells.

To deal with these problems, four finite element analyses have been completed for an acoustical tool with a typical thermal protection system. The model is a lumped mass-approximation of the real components in each section of the dewar. The analyses include boundary conditions that vary as a function of depth and time and material properties that vary as a function of temperature.

\section{BACKGROUND}

Previously, tools and electronics had survived the conditions in a FHS demonstration reservoir, which was $2930 \mathrm{~m}$ deep and $470 \mathrm{~K}$, but exposure to the 
higher temperatures and higher heat fluxes in the more recent deeper wells caused thermal failure of previously reliable systems.

The current thermal protection design places the electronics and a heat sink inside a tall, slender dewar that protects the package from radiation heat transfer. A cut-away illustration of the dewar, electronics, and heat sink sections is shown in Fig. 2. The sensors, batteries, circuit boards, and other components are mounted on brass rods that are held in place by copper bulkheads: The heat sink is tightly attached to the bulkhead nearest the open end of the dewar. The rods and bulkheads are the only high-conductance heat transfer paths from the electronics to the heat sink. The heat sink, filled with Woods Metal, is intended to absorb heat from the electronics, melting the Woods Metal at a temperature below the maximum temperature at which electronic components can be reliably exposed. Figure 3 illustrates the temperature history expected during operation. The temperature sensor mounted in the electronics section was expected to show a temperature increase up to the Woods Metal melting point, then a constant temperature, while the heat absorbed melts the Woods Metal, then finally another temperature increase after all the heat sink is completely melted.

There are several explanations for the observed temperature history: (a) the sensor failed, (b) the heat sink was already melted, (c) the heat transfer paths available for moving heat from electronics to heat sink was physically too small or their conductance was too small, and (d) the thermal potential between

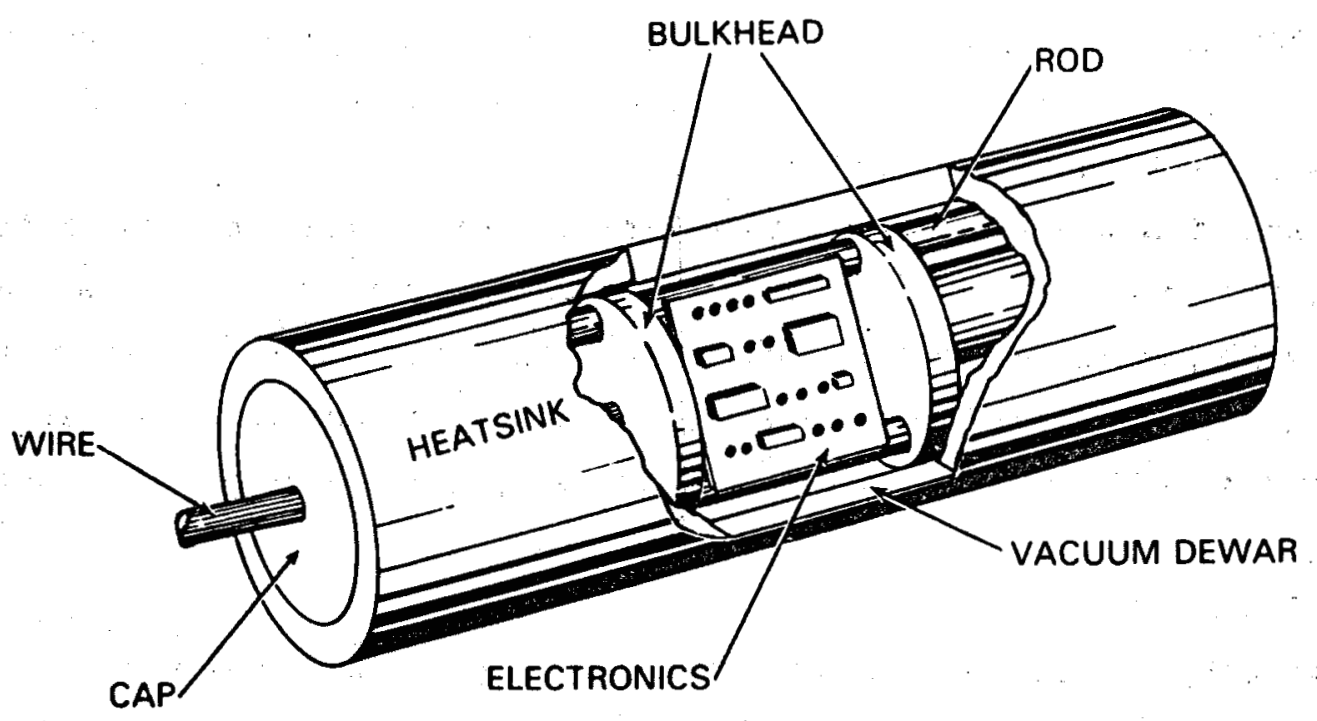

Fig. 2. Thermal protection system components. 


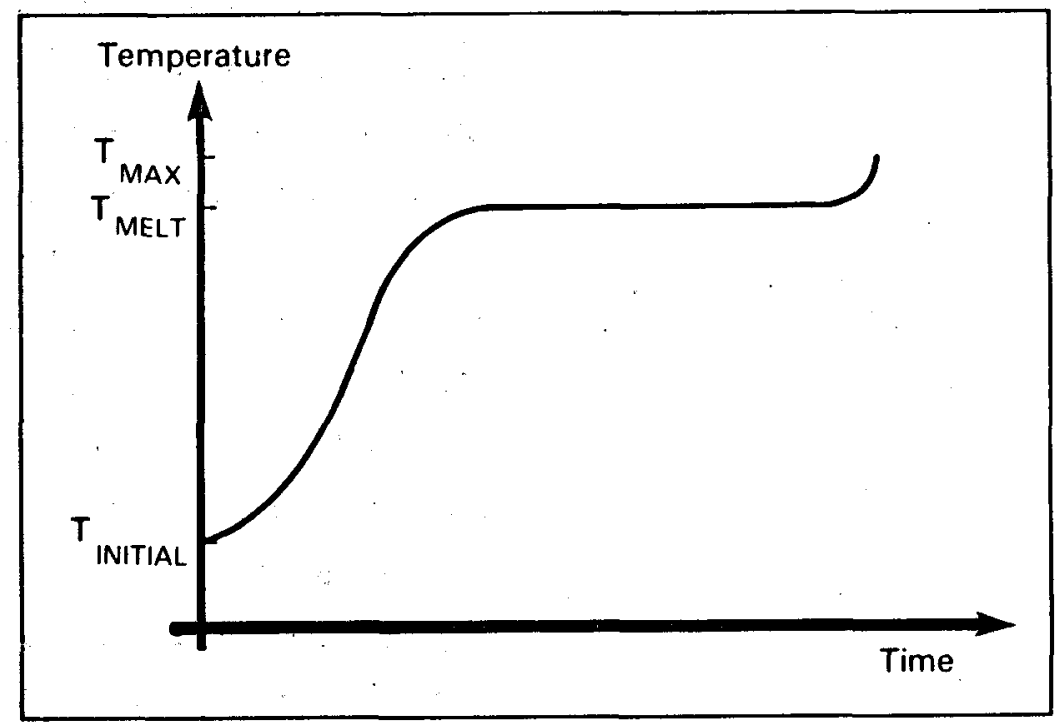

Fig. 3. Expected temperature history.

electronics and heat sink was too small or was in the wrong direction. This instrument was tested at $3340-\mathrm{m}$ depth where the temperature is $493 \mathrm{~K}$. It failed thermally after 2-1/3 h. The temperature sensor output, plotted in Fig. 4 , shows no flattening observed at $344 \mathrm{~K}$, the Woods Metal melting point.

Examination of the system immediately following the test showed that the heat-sink material was still solid and the sensor was found to be operational and accurate. Of the two remaining explanations, both involve determining the temperature of each subsystem inside the dewar -- batteries, heat sink, circuit boards, and stagnant air. This requires either a detailed thermal analysis or extensive instrumentation and testing of the system in simulated wellbore conditions.

\section{THERMAL ANALYSIS}

Four thermal analyses were made of the dewar section of the tool. Numerical calculations were made using the AYER ${ }^{4}$ finite element heat conduction code, which solves the generalized two-dimensional heat conduction equation implicitly. Meshes of the models were constructed using $20 N E,{ }^{5}$ a linear finite element mesher, and input data was prepared using a preprocessor program. A postprocessor program was used to plot the results, which are presented in the form of isotherm contours, temperature histories, heat flux histories, and plots of temperature versus position. 


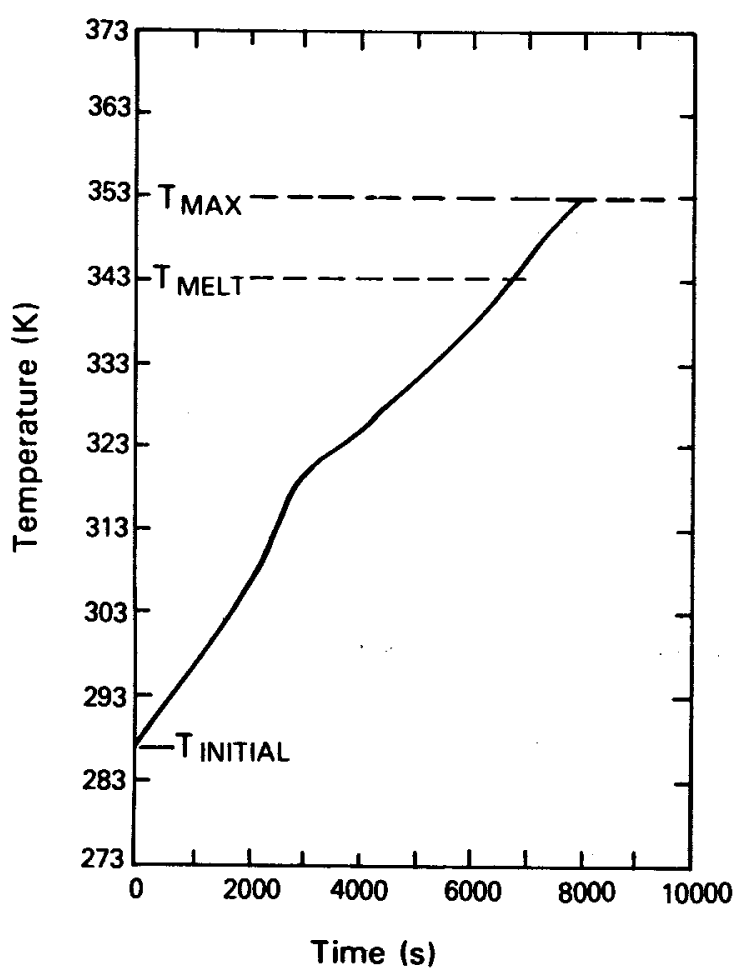

Fig. 4. Instrument test temperature history.
An axisymmetric and three

plane-section models were completed.

The right hand side of the

axisymmetric geometry is shown in Fig.

5. It assumes that there are no material or geometric variations in the $\theta$-direction, which is strictly true only for the heat-sink section. The battery and electronics sections have symmetry in approximately $180^{\circ}$ angular segments and were modeled as lumped masses with equivalent smeared thermal properties of the copper, steel, and phenolic components. The heat sink is a lumped mass containing steel and Woods Metal. Figures 6-8 illustrate the geometries used for the plane models of these sections. In

the plane models the lumped mass assumption was necessary only for the electronics section.

The material properties used throughout the analysis are given in Table I. Each equation was obtained by a least squares regression on the data. Several types of equations were tried, and the type which yielded the best "goodness of fit" parameter was chosen.

Physical dimensions of the instrument are as follows. The tool body is stock Shelby tubing with 11.43-cm 0.d. and 9.53-cm i.d. Centralizers keep a $0.32-\mathrm{cm}$ air space between the dewar and the inside tube surface. The dewar stands $96.52 \mathrm{~cm}$ tall and is $8.89-\mathrm{cm} 0 . d$. and $6.35-\mathrm{cm} 1 . \mathrm{d}$. The electronics consist of $14.48-\mathrm{cm}$-tall battery pack, several printed circuit boards, a steel cased inclinometer, and other batteries that all fit in a $6.35-\mathrm{cm} 0 . \mathrm{d} . \times 51.0-\mathrm{cm}-$ tali section. The heat sink is $6.03 \mathrm{~cm} \times 35.56 \mathrm{~cm}$ tall.

The partial differential equation of interest is 12

$$
\frac{\partial T}{\partial \theta}=\frac{K}{\rho c_{p}} \cdot \frac{1}{r}\left[\frac{\partial T}{\partial r}+\frac{\partial^{2} T}{\partial r^{2}}+\frac{\partial^{2}}{\partial z^{2}}\right] \text {, }
$$


TABLE I

MATERIAL PROPERTIES

\begin{tabular}{|c|c|c|c|c|}
\hline Material & $\begin{array}{l}\text { Density } \\
\left(\mathrm{kg} / \mathrm{m}^{3}\right)\end{array}$ & $\begin{array}{l}\text { Heat Capacity } \\
(\mathrm{J} / \mathrm{kg}-\mathrm{K})\end{array}$ & $\begin{array}{c}\text { Conductivity } \\
(W / m-K)\end{array}$ & Emmisivity $^{7}$ \\
\hline Stainless Steel ${ }^{6}$ & $8171-0.47^{* T}$ & 461 & 16.25 & 0.1 \\
\hline Brass $^{8}$ & 8554 & $571-0.43 * \mathrm{~T}$ & 103 & \\
\hline Copper 9 & 8940 & 380 & 398 & \\
\hline Woods Metal 10 & 9400 & 167.7 & 18.8 & \\
\hline $\mathrm{Bi}-\mathrm{Pb}$ Eutectic 8 & 10520 & $-128 \cdot 9+1.22 * \mathrm{~T}-1.34 \mathrm{E}-3 * \mathrm{~T}^{2}$ & $16.85+5.6 \mathrm{E}-3^{*} \mathrm{~T}$ & \\
\hline Phenolic ${ }^{11}$ & -1400 & 1130 & 108 & \\
\hline Air ${ }^{12}$ & $1.99-2.716 \mathrm{E}-3 * \mathrm{~T}$ & $972.42+0.106 * \mathrm{~T}$ & $7.43 \mathrm{E}-2+6.08 \mathrm{E}-5^{*} \mathrm{~T}$ & \\
\hline $\begin{array}{l}\text { Equivalent } \\
\text { Properties: } \\
\text { Battery Pack }\end{array}$ & 4611 & 414 & 377 & \\
\hline Electronics & 13830 & 393 & 214 & \\
\hline Heat Sink & 10350 & $-81 \cdot+1.22 * T-1 \cdot 34 E-3 * T^{2}$ & $16.85+5.6 \mathrm{E}-3^{* \mathrm{~T}}$ & \\
\hline
\end{tabular}




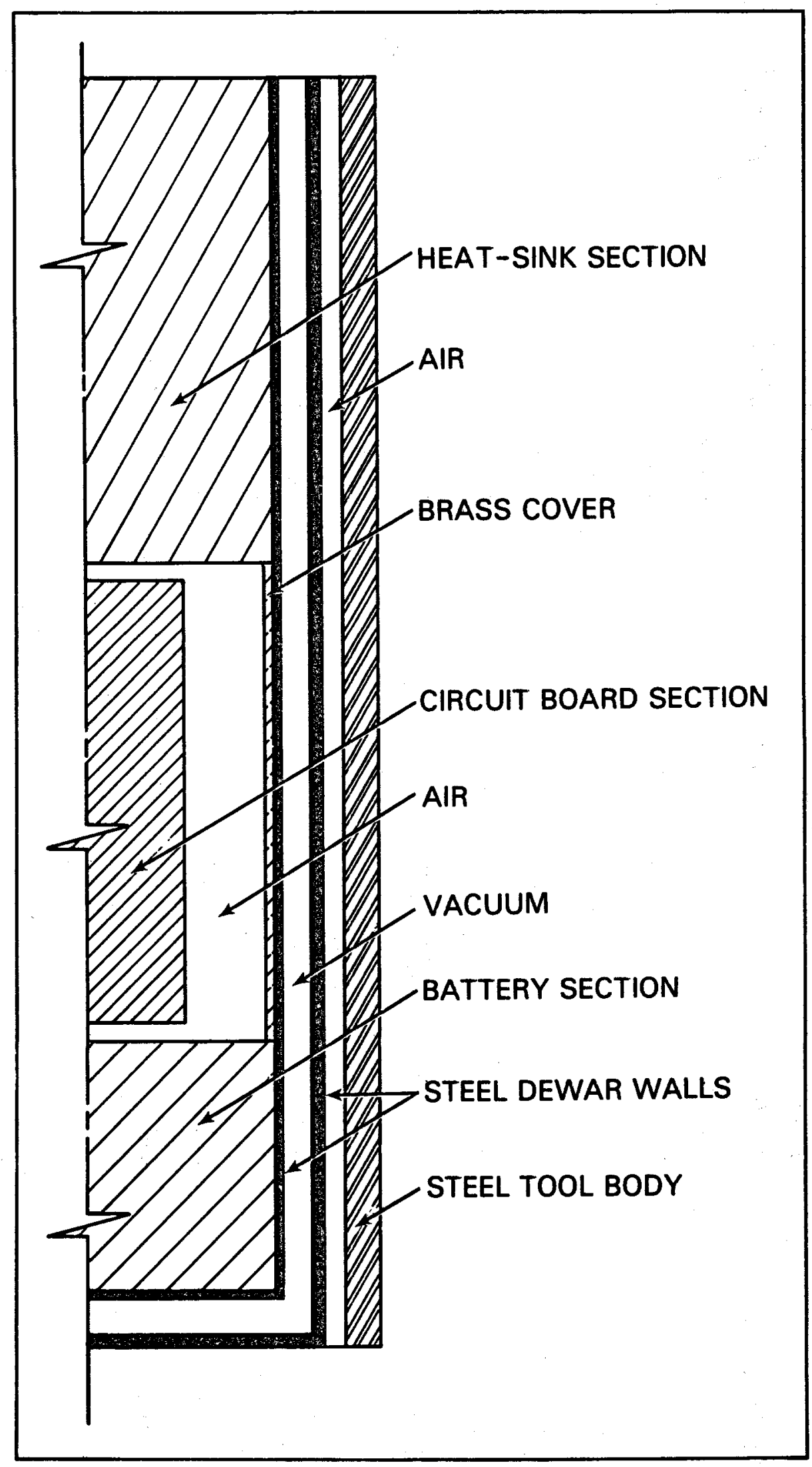

Fig. 5. Right hand side of axisymmetric model. 


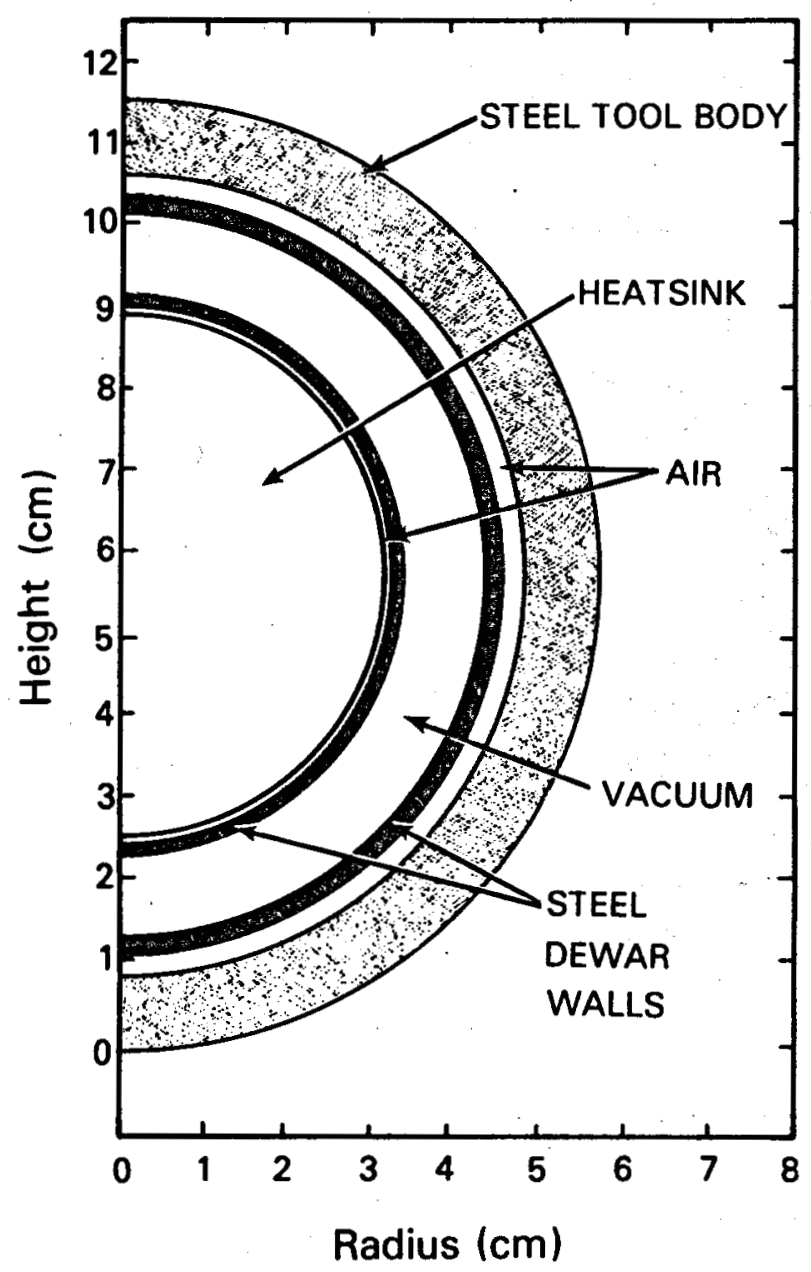

Fig. 6. Heat sink plane geometry model.

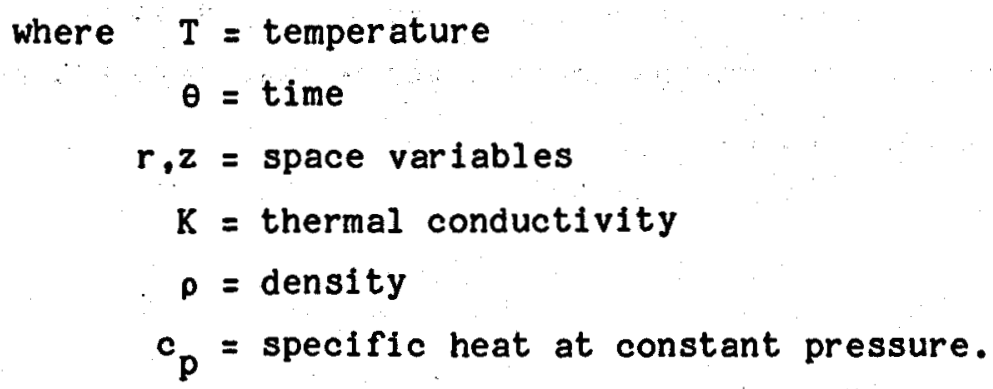

It is second-order in two independent space variables and time and is quasi linear because the material properties are allowed to vary with temperature. The initial conditions assumed for the entire mesh are

$$
T(r, z)=T_{0}=298 \mathrm{~K} .
$$




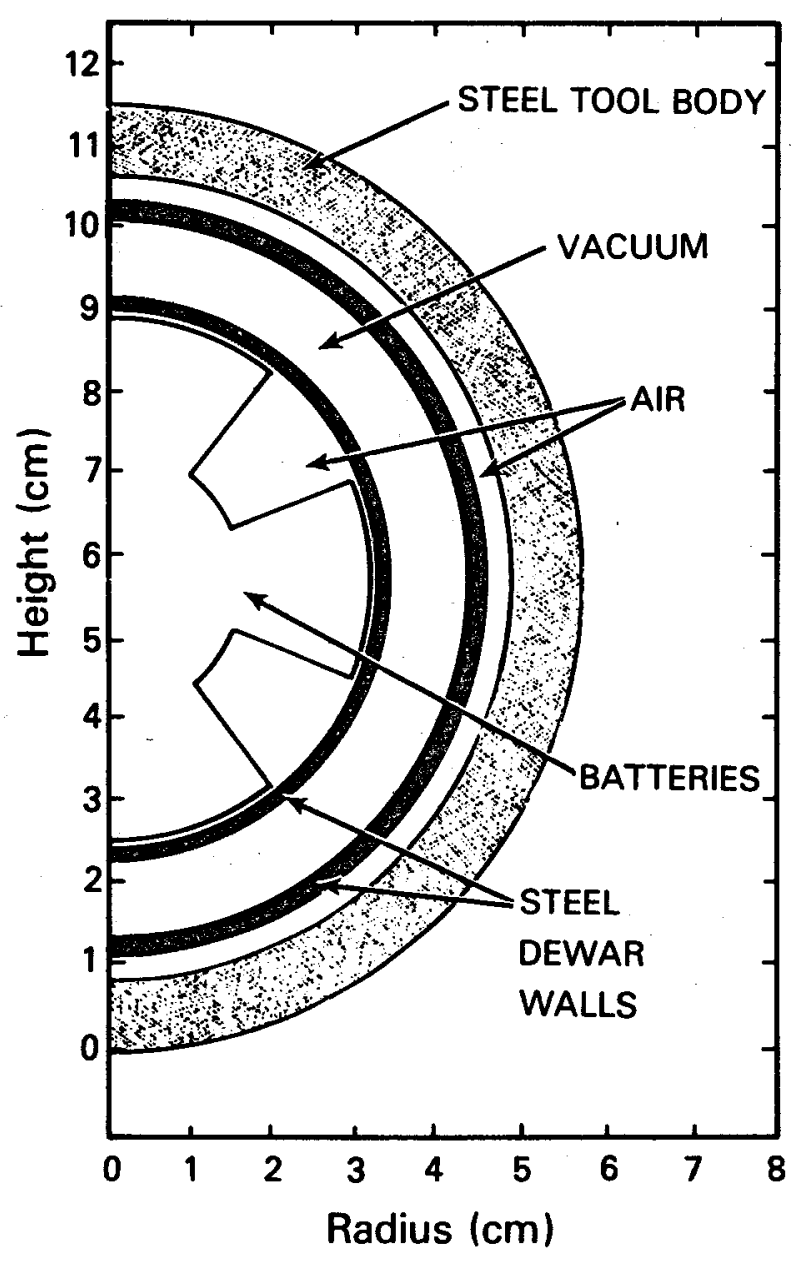

Fig. 8. Battery section plane geometry model.

The boundary condition on the outer tool body surface is based on the average trip velocity into the well and the background geothermal temperature gradient. The gradient is approximated by

$$
T_{\infty}=300.9+0.06 * V * \theta,
$$

where $T^{\infty}=$ free stream fluid temperature

$$
v=\text { tool velocity. }
$$

The film coefficient on the surface is calculated using the Dittus-Boelter equation $\star^{13}$ and solving for $\bar{h} c$; 


$$
\frac{h_{c} \cdot K}{D_{H}}=0.023 *\left[\frac{V \cdot D_{H} \cdot \rho}{\mu}\right] .8 *\left[\frac{c_{p} \mu}{K}\right]^{\cdot 33} \text {, }
$$

$$
\text { where } \begin{aligned}
\bar{h}_{c} & =\text { film coefficient } \\
D_{H} & =\text { hydraulic diameter } \\
\mu & =\text { dynamic viscosity }
\end{aligned}
$$

The boundary condition on the outer tool body surface is then

$$
-\left.K^{\frac{\partial T}{\partial r}}\right|_{r=r_{0}}=\hbar_{c}\left[T\left(r_{0}, z\right)-T \infty\right] .
$$

At the upper end of the dewar, heat is transferred through a cork plug for which

$$
\bar{h}_{\text {top }}=\frac{\text { Kcork }}{\text { Lcork }}=1.7 \frac{\text { watts }}{\mathrm{m}^{2}}
$$

at a $T_{\infty}$ approximated by $T\left(r_{0}, l\right)$ so that

$$
-\left.\frac{K}{\partial z}\right|_{z=\ell}=\bar{h}_{\text {top }}\left[T(r, \ell)-T_{\infty}\right] \text {. }
$$

At the bottom end of the dewar heat is transferred through a $4.2-\mathrm{cm}$ air gap for which

$$
\hbar_{\text {bottom }}=\frac{\text { Kair }}{\text { Lair }}=0.75 \frac{\text { watts }}{\mathrm{m}^{2}}
$$

at a $T_{\infty}$ approximated by $T\left(r_{0}, 0\right)$ so that

$$
-\left.K^{\frac{\partial T}{\partial z}}\right|_{z=0}=\bar{h}_{\text {bottom }}\left[T(r, 0)-T_{\infty}\right] \text {. }
$$

Solution of the partial differential equation was accomplished numerically. 
IV. RESULTS

The purpose of this investigation was to determine the input heat fluxes and the temperature field in the tool as a function of time. Figures 9, 10, and 11 show the temperature on the outer tool surface and the resulting heat fluxes.

At the given velocity, the tool reaches station at $4420 \mathrm{~s}$ where the temperature is $502 \mathrm{~K}$ (Fig. 9). The resulting heat flux is plotted in two parts corresponding to the time interval to reach station and the time interval while parked. Figure 10 shows a large heat flux because the tool starts at a low initial temperature and its boundary is subjected to a rapidly increasing geothermal gradient. A curve fit was made to the flux-time results using linear regression for times larger than $200 \mathrm{~s}$ and yielded

$$
\begin{aligned}
& \begin{aligned}
& Q / A=1350.9+4.696 E-2^{*} \theta \cdot=f_{1}(\theta), \\
& \text { where } Q / A=\text { heat flux } \\
& \theta=\text { time. }
\end{aligned}
\end{aligned}
$$

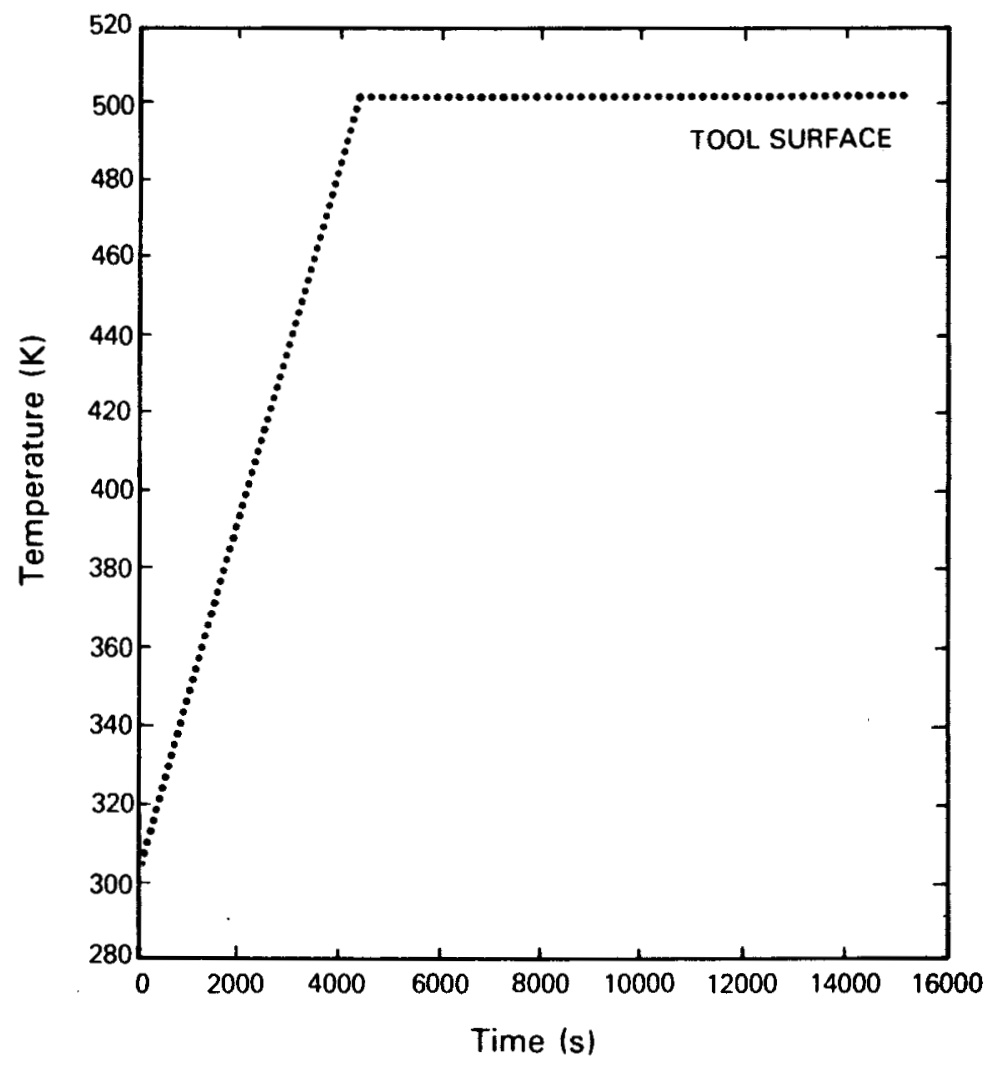

Fig. 9. Tool surface temperature. 
After reaching station, the input heat flux, shown in Fig. 11, drops to $6 \%$ of its previous value. This flux-time history yields a curve fit of the form

$$
Q / A=187.82 e^{-8.69 E-5 \theta}=f_{2}(\theta) \text {. }
$$

The energy input per unit area for the trip into the well is

$$
\int_{0}^{t} f_{1}(\theta) d \theta=6.4 \times 10^{6} \frac{\mathrm{J}}{\mathrm{m}^{2}} .
$$

Hand calculation to estimate the expected temperature change for the total mass, an equivalent specific heat and the above energy input gives

$$
\Delta T=148 \mathrm{~K} .
$$

Examination of the 1sotherm contours in Fig. 12 shows that the tool body experienced a $189 \mathrm{~K}$ temperature rise but all other components stayed relatively cool. The steel tubular tool body constitutes a major part of the thermal mass of the system, protecting the electronics for the trip into the well.

The energy input per unit area while parked on station until failure is $3.37 \mathrm{E}+6 \mathrm{~J} / \mathrm{m}^{2}$. In this case, the hand calculation of a temperature change is untenable because of the radiation across the dewar vacuum leads to a $\mathrm{T}^{4}$ term.

The temperature field in the electronics section at $\theta=4421 \mathrm{~s}$ is shown in Fig. 11. The electronics experience a $5 \mathrm{~K}$ temperature $\mathrm{rise}$ as compared to $30 \mathrm{~K}$ for the surrounding air. Figure 13 shows the plots of temperature versus radial position through this section for several times during the simulation. Each portion -- electronics, air, dewar walls, vacuum, and tool body -- is marked and reveals the degree of resistance offered by the dewar and the layers of stagnant air. The electronics are indeed the coolest objects in the tool. The temperature sensor reads the air temperature rather than circuit board temperature and might be considered too conservative or in error. Since the electronics are modeled as a lumped mass with equivalent thermal properties, only a much finer analysis would give a better definition of actual temperature of components mounted on the circuit boards. Figure 14 shows the isotherms in 


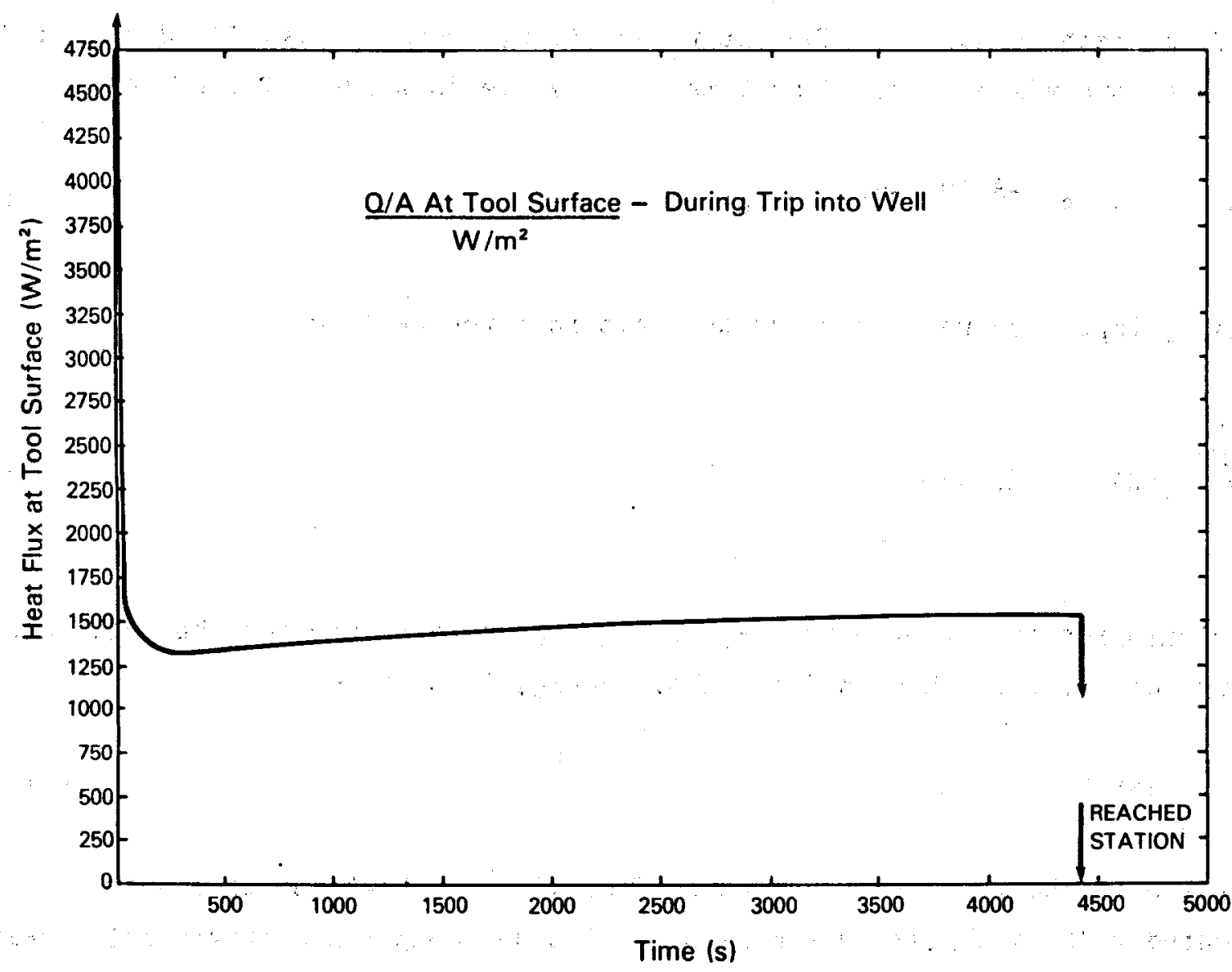

Fig. 10. Input heat flux at tool surface during trip into well.

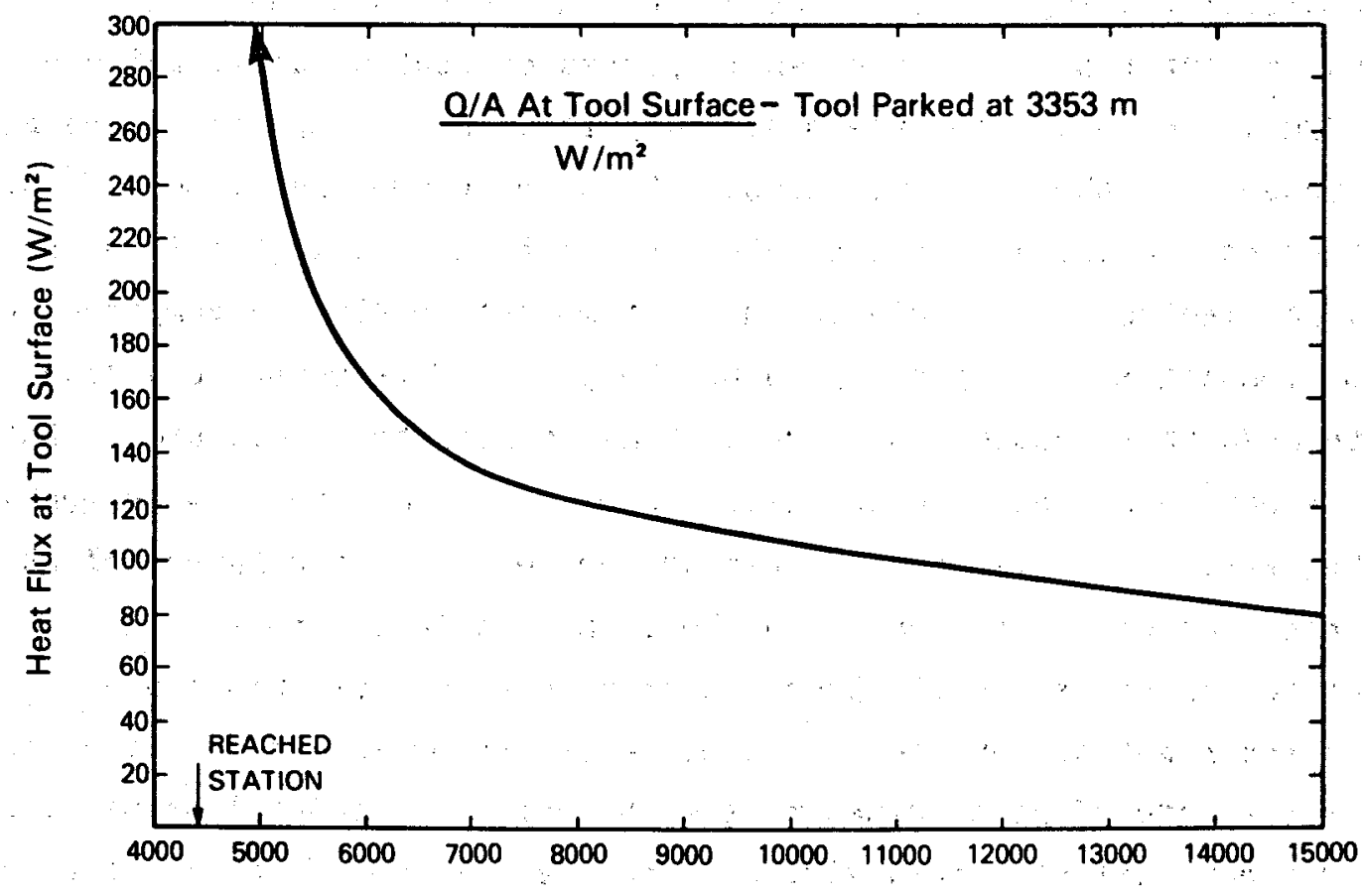

Time (s)

Fig. 11. Input heat flux at tool surface while parked on station. 


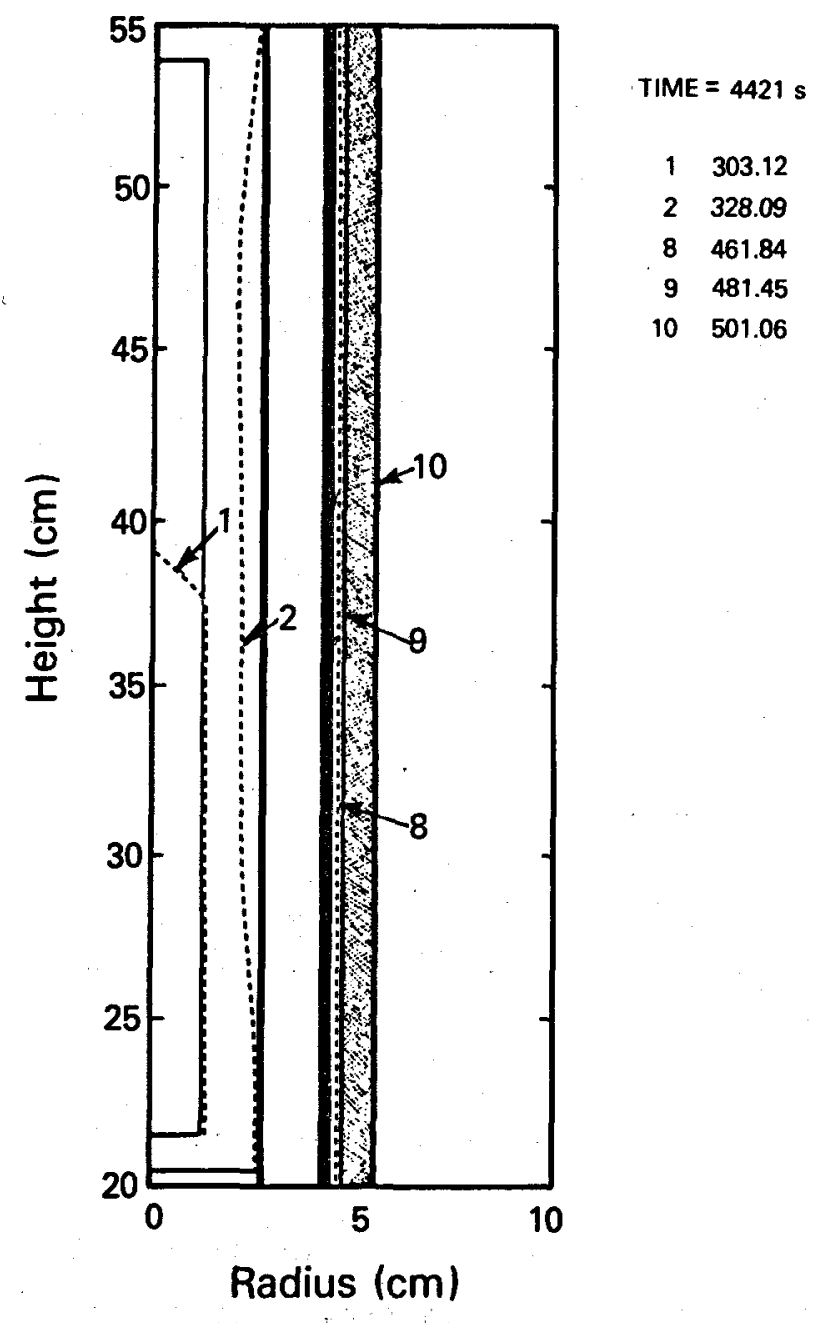

Fig. 12. Isotherm contours in electronlcs section at time=4421 s.

the electronics section at $\theta=8020 \mathrm{~s}$, with bulk air and electronics temperature of 354 and $321 \mathrm{~K}$. Because $353 \mathrm{~K}$ is the maximum reliable operating temperature, the time limit is reached at approximately $8500 \mathrm{~s}$, which correlates with measurements taken during the instrument development test. Assuming that the tool is removed after $8500 \mathrm{~s}$ at the same velocity, the air and electronics temperature rise to 368 and $348 \mathrm{~K}$, respectively, (Fig. 15) leaving very little margin between the calculated and maximum operating temperatures. Then, using the air temperature to determine time of retrieval is reasonable.

To investigate the thermal potentials between sections in the dewar assuming the tool remains in the well, a temperature history at each section and on the boundary is plotted in Fig. 16. As time $=8921 \mathrm{~s}$, the heat sink and 


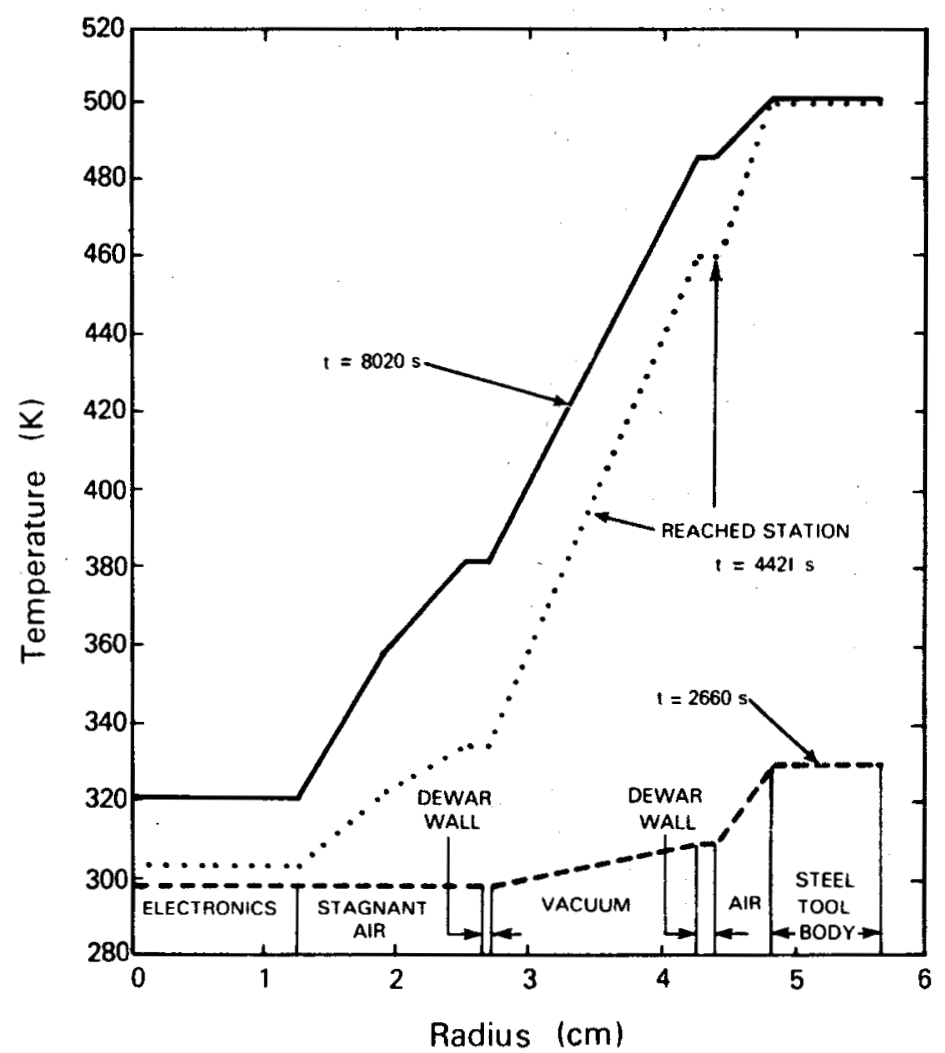

Fig. 13. Temperature vs radius at time $=660 \mathrm{~s}, 4421 \mathrm{~s}$, and $8020 \mathrm{~s}$.

batteries are 48 and $57 \mathrm{~K}$ warmer than the electronics. The existing thermal potentials will move heat into the electronics rather than from electronics to heat sink. The available paths for heat transfer have a conductance of $4.71 \times 10^{-2} \frac{\mathrm{W}}{\mathrm{m}^{2}}$ which can transfer only $2.5 \mathrm{~W}$ at the given potentials.

Recalling the possible explanations for the measured temperature history, both (c) and(d) have been shown to contribute to thermal failure.

\section{DESIGN IMPROVEMENTS}

Design improvements made to the thermal protection system involved increasing both the conductance and the thermal potential between electronics and heat sink.

Heat pipes replaced the brass rod mounting rails. For a heat pipe operating at $323 \mathrm{~K}$, the conductance or axial heat flux is $4 \times 10^{4} \mathrm{~W} / \mathrm{m}^{2}$, which is vastly larger than the conductance of long, small diameter brass rods. ${ }^{14}$ 


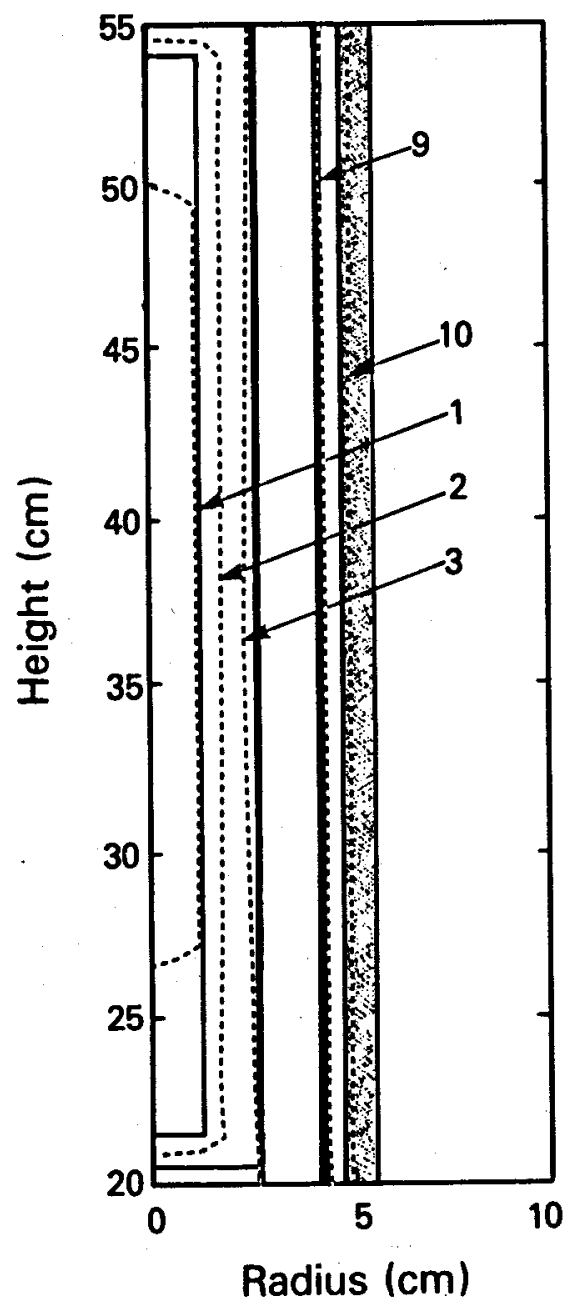

$$
\begin{array}{rc}
\text { TIME } & =8020 \mathrm{~s} \\
1 & 320.98 \\
2 & 347.94 \\
3 & 374.90 \\
9 & 487.32 \\
10 & 501.94
\end{array}
$$

Fig. 14. Isotherm contours in the electronics section at time $=8020 \mathrm{~s}$.

Without resizing the dewar, the thermal capacity of the heat sink is limited by its volume. An increase in thermal capacity must be a result of increasing the $\rho c_{p}$ and $\rho^{*} L_{\text {fusion }}$ products of the material. Also, any materials considered must have a melting point below $353 \mathrm{~K}$, the maximum electronics temperature. For each material considered, a calculation was made to determine the enthalpy increase of the solid, energy absorbed in melting, and enthalpy increase of the liquid between the temperature limits of 273 and $353 \mathrm{~K}$. Material properties and results are listed in Table II. Tap water was chosen as the replacement heat sink material, after considering cost, availability, and handling difficulties.

The choice of a heat sink material with a melting point below $353 \mathrm{~K}$ provides a much larger thermal potential in the right direction -- from the 


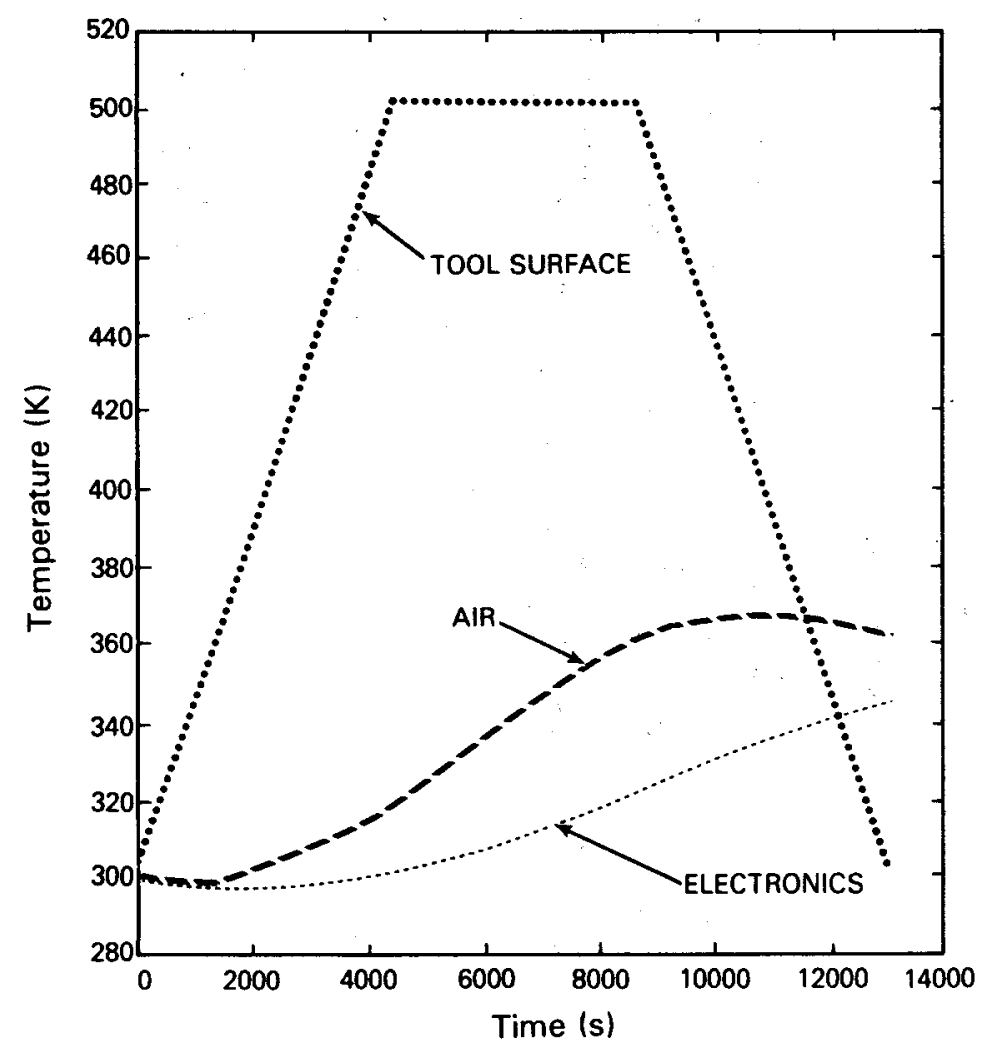

Fig. 15. Round trip temperature history for tool surface, electronics and stagnant air.

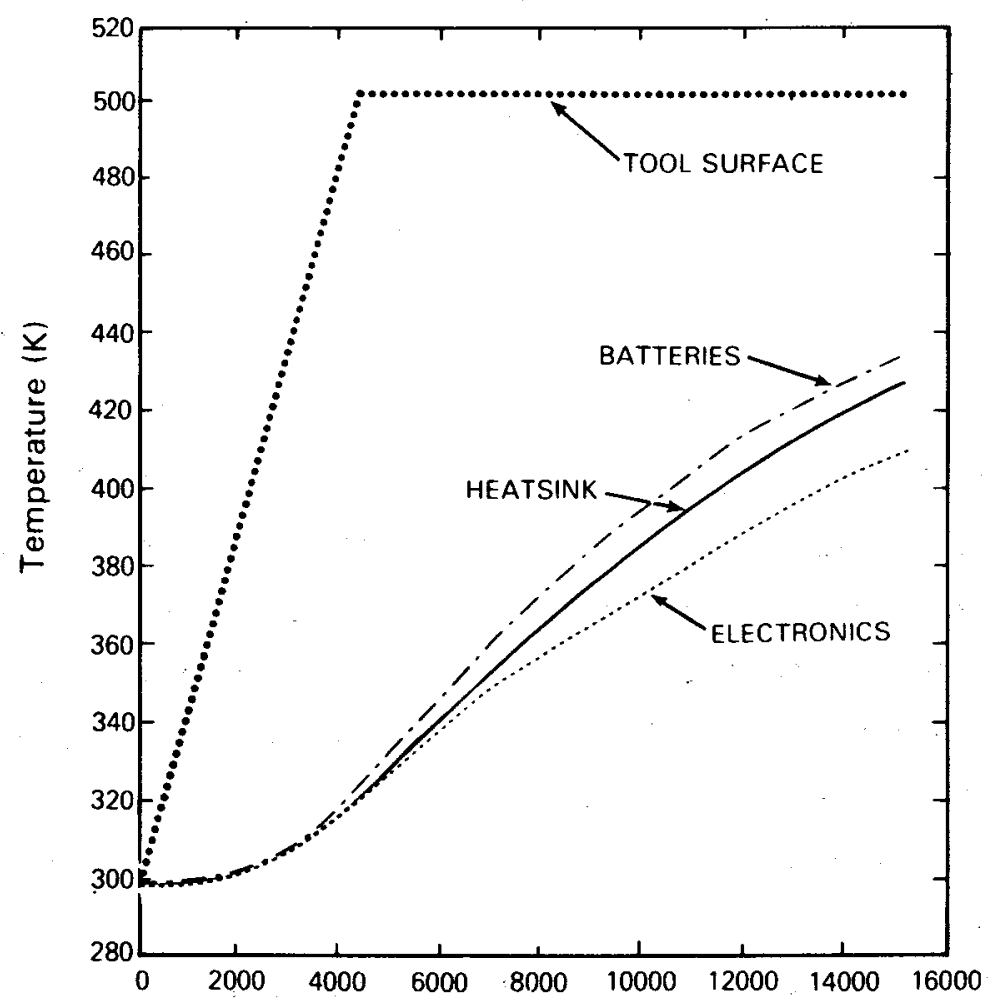

Time (s)

Fig. 16. Temperature history to demonstrate thermal potential between sections. 
TABLE II.

HEAT SINK MATERIAL

\begin{tabular}{|c|c|c|c|c|c|}
\hline Material & $\begin{array}{c}\text { Tmelt } \\
(\mathrm{K}) \\
\end{array}$ & $\begin{array}{l}\text { Density } \\
\left(\mathrm{kg} / \mathrm{m}^{3}\right)\end{array}$ & $\begin{array}{c}\text { Specific } \\
\text { Heat } \\
(\mathrm{J} / \mathrm{kg}-\mathrm{K}) \\
\end{array}$ & $\begin{array}{c}\text { Latent } \\
\text { Heat } \\
\left(\mathrm{J} / \mathrm{kg} \times 10^{5}\right) \\
\end{array}$ & $\begin{array}{c}\text { Heat } \\
\text { Absorbed } \\
\left(\mathrm{J} \times 10^{5}\right) \\
\end{array}$ \\
\hline $\begin{array}{c}\text { Eisocune } \\
\mathrm{C}_{20} \mathrm{H}_{42}\end{array}$ & 310 & 880 & 154.8 & 2.46 & 1.59 \\
\hline Woods Metal ${ }^{16}$ & 344 & 9400 & 167.4 & 0.325 & 2.88 \\
\hline Galli um ${ }^{16}$ & 303 & 6095 & 372 & 0.445 & 3.81 \\
\hline Ice ${ }^{12}$ & 273 & 9130 & 192 & 3.35 & 4.58 \\
\hline
\end{tabular}

electronics to the heat sink. For ice, the temperature difference is $0<\Delta \mathrm{T}<80^{\circ}$ and diminishes with time after the ice melts and the entire package heats up. These three improvements made to the thermal protection system changed its operation by allowing some energy to be absorbed as latent heat in addition to the energy already absorbed as enthalpy increases. The tool survival at given temperatures was increased by a factor of 4 and thus allowed reasonable time for making necessary measurements.

\section{REFERENCES}

1. J. C. Rowley and R. S. Carden, "Drilling of Hot Dry Rock Geothermal Energy Extraction Well EE-3," Los Alamos National Laboratory report LA-9512-HDR (August 1982).

2: C. Helmick, S. Koczan, and R. Pettitt, "Planning and Drilling Geothermal Energy Extraction Hole EE-2," Los Alamos National Laboratory report LA-9302-HDR (April 1982).

3. R. A. Pettitt, "Planning, Drilling, Logging and Testing of Energy Extraction Hole EE-1, Phase I and II," Los Alamos Scientific Laboratory report LA-6906-MS (August 1977).

4. R. G. Lawton, "The AYER Heat Conduction Computer Program," Los Al amos Scientific Laboratory report LA-5613-MS (May 1974).

5. M. J. Berger, "ZONE - A Finite Element Mesh Generator," Lawrence Livermore Laboratory report UCID-17139, Rev. 1 (March 12, 1980). 
6. Y. S. Touloukian, Editor, "Ferrous Alloys," Thermophysical Properties of High-Temperature Solid Materials 3, 1967, p $145,161,174$.

7. Y. S. Touloukian and D. P. DeWitt, "Thermal Radioactive Properties-Metallic Elements and Alloys," Thermophysical Properties of Matter 7, 1970, p 1210.

8. Y. S. Touloukian and E. H. Buyco, "Specific Heat-Metallic Elements and Alloys," Thermophysical Properties of Matter 4, 1970, p 348.

9. Y. S. Touloukian, "Elements," Thermophysical Properties of High-Temperature Solid Materials 1, 1967, p 452-461.

10. Cerro Metal Products, "Cerro Alloy Physical Data," Division of Cerro Corporation, Bellefonte, Pennsylvania.

11. D. J. Duffin, Laminated Plastics, (Reinhold Publishing Corporation, New York, 1966), p 110-111.

12. F. Kreith, Principles of Heat Transfer, (Intext Educational Publishers, New York, 1973), p 636, 126.

13. Max Jakob, Heat Transfer, (John Wiley and Sons, Inc., New York, 1949), p 547.

14. P. Dunn and D. A. Reay, Heat Pipes, (Pergamon Press, Oxford, 1978), p 106.

15. E. W. Bentilla, K. F. Starrett, and L. E. Karre, "Research and Development Study on Thermal Control By Use of Fusible Materials," Northrop Space Laboratories report NSL-65-16-1 (April 1966).

16. Metal Specialties, "Properties of Metal Specialties Alloys," Fairfield, Connecticut. 